\section{SNAPSHOT Asia choked by peat smog}

Countries in southeast Asia are planning drastic action in a bid to combat peat fires that have smothered the region in a thick haze.

Satellite images taken on 12 August (see picture) show that a soupy smog now covers much of Malaysia and Indonesia. The smog is being generated by smouldering peat bogs on the islands of Borneo and Sumatra, which are set alight each year as farmers clear their lands (see Nature 432, 144-146; 2004).

The smoke has been so bad that schools and businesses have been forced to close and there has been a dramatic rise in respiratory ailments, according to reports from the region.

Indonesian authorities announced last week that they would prosecute ten plantation owners for lighting illegal fires on their land. The Malaysian government, meanwhile, is planning to seed rain clouds in the hope that they will help to clear the haze from the air.

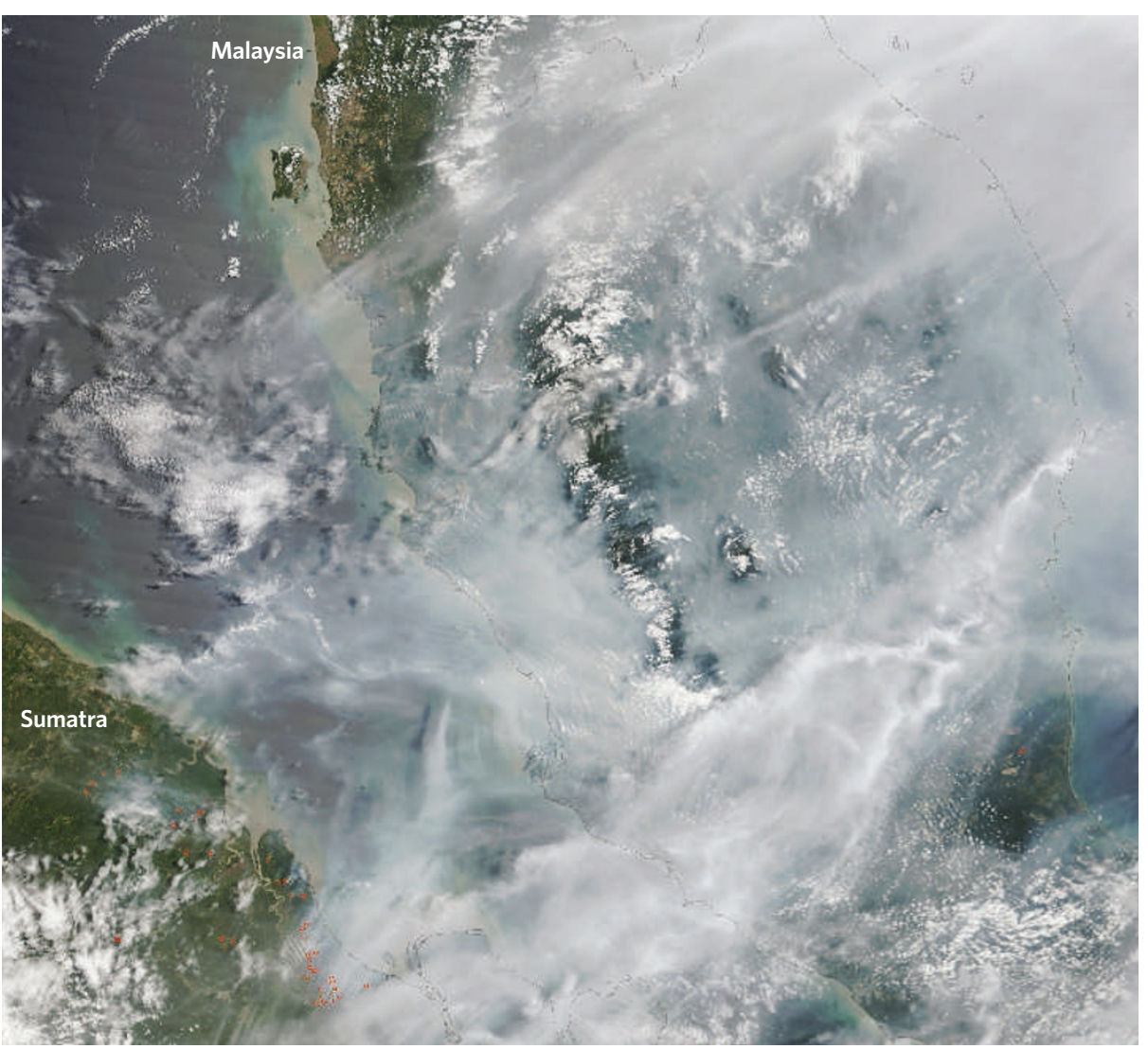

\title{
Warning system makes the grade during quake
}

\section{TOKYO}

The earthquake that hit northeast Japan last week gave scientists an opportunity to test their early warning system. About 140 schools, government agencies and companies in Sendai, the region's major city, were warned about the 7.2 magnitude quake up to $16 \mathrm{sec}$ onds before it arrived.

The quake hit at 11:46 local time on 16 August, about 80 kilometres off the coast of Miyagi state, and caused around 70 injuries. Officials at the Japan Meteorological Agency, which runs the early warning system, say that they are pleased with the accuracy and speed of the warning, although it will still be several years before the system is fully operational. The agency has been testing the system in Sendai since March, and plans to

\section{"There's no} other way to protect our

lives." country pick up the weak primary waves, which move outwards from the epicentre at 6-8 kilometres per second. A computer at the agency's headquarters then calculates how the slower but stronger shear waves, which can cause serious damage, will spread. If the quake is predicted to be more than magnitude 4 , it sends out information about the magnitude and estimated arrival time.

"We are now examining how to make the warnings most useful," says Katsuyuki Abe, a seismologist at the University of Tokyo. Apart from warning the public to take cover, the information could be used to stop trains or elevators, or even get surgeons to halt operations.

Many trains and elevators in Japan already have systems to slow them down as soon as a quake hits. expand it across the country for testing by March next year.

The system takes advantage of a difference in speed between two kinds of seismic waves that make up a tremor. When a quake occurs, hundreds of detectors scattered across the haps magnitude 8 or more, is expected to hit the nation within the next 30 years. The government's Central Disaster Prevention Council predicts that about 9,200 people would die if such a quake hit off the coast of the Tokai region, west of Tokyo, but officials hope that the early warning system, together with ongoing monitoring of the strain in the tectonic plates, could significantly help to reduce that toll .

The latest success will help build the credibility of the warning system, which has delivered a few false alarms during thunderstorms. But improvements are still needed. At a school in Sendai, the warning signal was meant to be relayed to loudspeakers to tell the children to take shelter, but a computer error meant it didn't work. Fortunately, the children were on their summer holidays at the time.

"It's still at the development stage," admits Kosaku Yamaguchi, a senior researcher at the Real-time Earthquake Information Consortium. "But we are getting to know what the problems are. There's no other way to protect our lives."

Ichiko Fuyuno
Japan is one of the world's most earthquakeprone countries. The next 'big' quake, of per-
But extra seconds could reduce the amount of damaged track that trains travel over, for example, or give elevators more time to reach the nearest floor.

Ther Nature Publishing Group 